\title{
COMPARATIVE STUDY OF TWO METHODS OF FEMALE STERILIZATION-PNS (MINILAP TUBECTOMY) AND DPLS (DOUBLE PUNCTURE LAPAROSCOPIC STERILIZATION)
}

\author{
G. Mahalakshmi1, Sandhya Dixit ${ }^{2}$
}

${ }^{1}$ Associate Professor, Department of Obstetrics \& Gynaecology, Gandhi Medical College/Hospital.

${ }^{2}$ Assistant Professor, Department of Obstetrics \& Gynaecology, Osmania Medical College/Hospital.

\section{ABSTRACT}

\section{OBJECTIVE}

To compare the technique of PNS and DPLS and to highlight the advantages and disadvantages of each method.

\section{METHODS}

We performed 1800 mini lap tubectomies and 1800 DPLS and compared the events during the operation, post-operative events and complications.

\section{RESULTS}

Most of the women were between 22 and 25 years and opted for sterilization with two children in both the groups. More incidence of haemorrhage, injury to bladder in two cases of PNS and intestinal injury in one case of PNS is seen. More congenital anomalies were observed in DPLS cases (Co-incidental finding). More post-operative pain requiring analgesics for a longer period and surgical site infection was seen in PNS. Omental prolapse was seen in one case of DPLS. Incisional hernia was seen in two cases of PNS.

\section{KEYWORDS}

PNS-Postnatal Sterilization, DPLS-Double Puncture Laparoscopic Sterilization, Interval sterilization, Minilap Tubectomy.

HOW TO CITE THIS ARTICLE: Mahalakshmi G, Dixit S. Comparative study of two methods of female sterilization-PNS (minilap tubectomy) and DPLS (double puncture laparoscopic sterilization). J. Evolution Med. Dent. Sci. 2016;5(42):2611-2613, DOI: $10.14260 /$ jemds/2016/610

\section{INTRODUCTION}

Female sterilization is the permanent method of contraception. Today, there is a pressing need for limiting the family size at a personal level and for the control of population at national level. The need of birth control at a personal level has arisen through increased cost of living, scarcity of accommodation, a desire for better education of children in the present competitive world and an overall desire for an improved standard of living. Tubal ligation can be done at any convenient time to the client. Post-natal sterilization (PNS) is done within one week of delivery, when the woman is already hospitalized. Interval sterilization is done when the woman is not pregnant or any time six weeks after delivery. It can be combined with caesarean section and MTP. Interval sterilizations are mostly performed by DPLS method. Postpartum or postnatal sterilization is done by mini laparotomyPomeroy technique.

\section{MATERIALS AND METHODS}

A prospective multicentric study is done comparing 1800 cases of DPLS with 1800 cases of PNS between July 2006 and June 2010. Cases are selected randomly with comparative age and parity matched and with good general condition. The criteria noted are Age, Parity, Pre-operative condition, Intraoperative events, Post-operative events, Duration of hospital stay, Condition at discharge and Client satisfaction.

Financial or Other, Competing Interest: None.

Submission 16-03-2016, Peer Review 14-04-2016,

Acceptance 20-04-2016, Published 26-05-2016.

Corresponding Author:

Dr. G. Mahalakshmi,

H. No: 2-2-647/276,

Srinivasnagar Colony,

Bagh Amberpet,

Hyderabad-500013.

E-mail: golimahalakshmi8@gmail.com

DOI: $10.14260 /$ jemds/2016/610
All of them were followed up to two weeks. Places of study included Government Maternity Hospital, Sultan Bazaar under Osmania Medical College, Gandhi Medical College, Hyderabad and rural camps in Ranga Reddy districts in Telangana.

\section{Exclusion Criteria}

Associated Medical Disorders, Postnatal Morbidities, Post Abortal Sterilizations and Interval Minilap Tubectomies.

\section{Inclusion Criteria}

PNS - within 72 hours of Delivery

DPLS (Interval Sterilization)

- Six weeks after delivery

- Regularly menstruating during the follicular phase of the menstrual cycle

- Irrespective of the cycle of menstruation when there is a history of abstinence or use of any temporary contraceptive method.

- If the woman comes three months after delivery for DPLS during lactational amenorrhoea, they were given progesterone withdrawal and taken up for surgery after withdrawal bleeding to rule out pregnancy.

All clients were subjected for general examination, vital data recording per abdomen and per vaginal examination. Reaffirmed their willingness for undergoing permanent contraception (PNS or DPLS) counselling regarding the procedure and its consequences were explained. Mandatory tests done were HB\%, urine for albumin and sugar, BT/CT. Ultrasound examination of the client and urine for pregnancy tests were done wherever necessary. Haemoglobin of 8 gms was taken as mandatory, pulse rate, temperature, respiratory rate, blood pressure and heart and lungs were examined.

\section{RESULTS}

Results were calculated and tabulated as shown. 
In both the groups, maximum no. of surgeries were done in the age group of 22-25 years.

\begin{tabular}{|c|c|c|c|c|}
\hline Age & PNS & Percentage & DPLS & Percentage \\
\hline $22-25$ & 1355 & 75.2 & 1156 & 64.2 \\
\hline $26-30$ & 326 & 18.1 & 412 & 22.8 \\
\hline $31-35$ & 98 & 5.4 & 213 & 11.8 \\
\hline$>35$ & 21 & 1.1 & 19 & 1.0 \\
\hline Total & $\mathbf{1 8 0 0}$ & $\mathbf{1 0 0}$ & $\mathbf{1 8 0 0}$ & $\mathbf{1 0 0}$ \\
\hline \multicolumn{6}{|c}{ Table 1: Table showing Age-Wise Distribution } \\
\hline
\end{tabular}

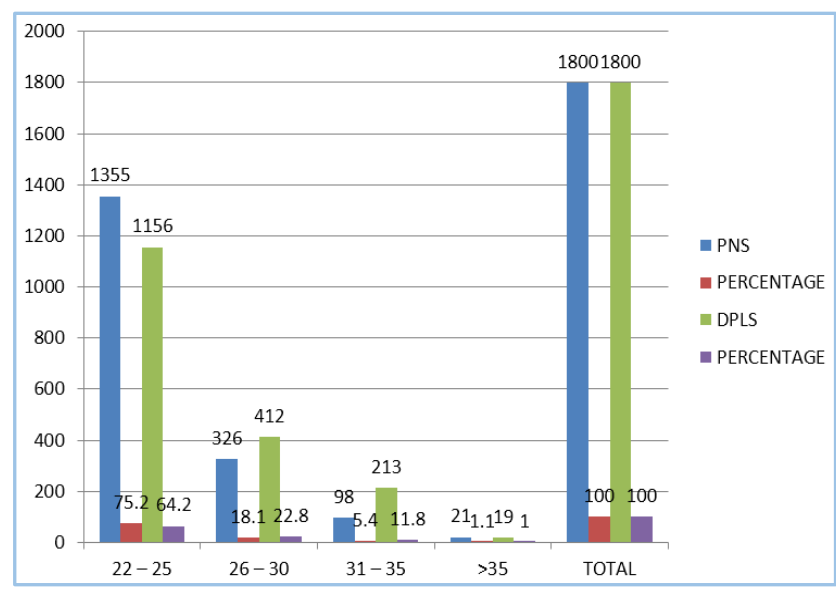

Maximum clients preferred only two children

\begin{tabular}{|c|c|c|c|c|}
\hline Parity & PNS & Percentage & DPLS & Percentage \\
\hline P1 & NIL & 0 & 22 & 1.2 \\
\hline P2 & 1033 & 57.3 & 1132 & 62.9 \\
\hline P3 & 618 & 34.3 & 424 & 23.5 \\
\hline P4 & 116 & 6.4 & 213 & 11.8 \\
\hline P5 & 33 & 1.8 & 9 & 0.5 \\
\hline Total & $\mathbf{1 8 0 0}$ & $\mathbf{1 0 0}$ & $\mathbf{1 8 0 0}$ & $\mathbf{1 0 0}$ \\
\hline \multicolumn{4}{|c|}{ Table 2: Table showing Parity-Wise Distribution } \\
\hline
\end{tabular}

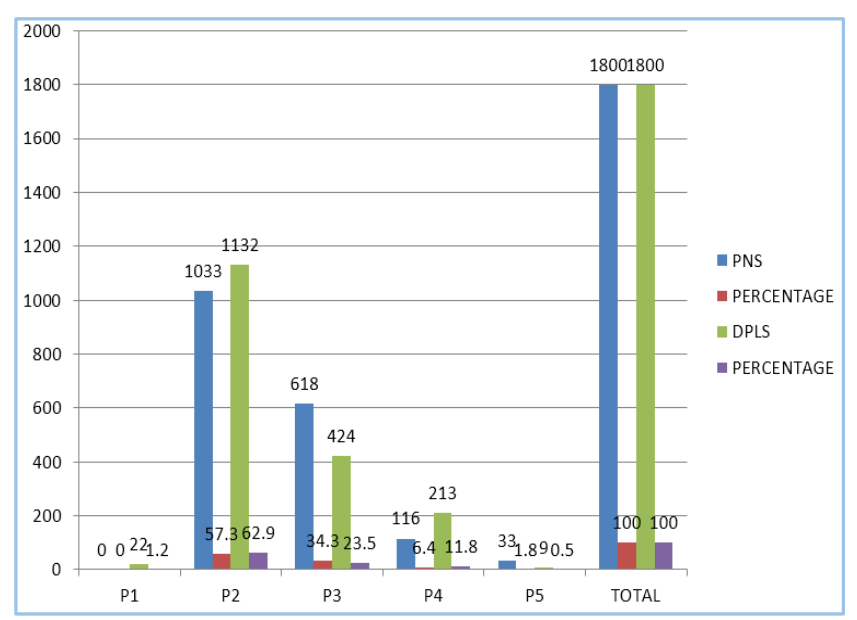

Intraoperative findings showed more incidence of haemorrhage and injury to mesosalpinx, injury to bladder and intestine in PNS. Coincidentally, Mullerian anomalies, other pelvic masses were observed more during DPLS.

\begin{tabular}{|c|c|c|}
\hline Intraoperative Findings & PNS & DPLS \\
\hline Haemorrhage & 12 & 2 \\
\hline Injury to Mesosalpinx & 15 & 3 \\
\hline $\begin{aligned} \text { Injury to Viscera } \\
\bullet \quad \text { Bladder } \\
\bullet \quad \text { Intestine }\end{aligned}$ & $\begin{array}{l}2 \\
1\end{array}$ & $\begin{array}{l}\text { NIL } \\
\text { NIL }\end{array}$ \\
\hline Duration of Surgery & $15-25$ mins & $\begin{array}{c}5-10 \\
\text { mins }\end{array}$ \\
\hline Incidental Pathology Noted & $\begin{array}{c}\text { Ovarian } \\
\text { cysts - } 8 \\
\text { Hydrosal- } \\
\text { pinx - } 4\end{array}$ & $\begin{array}{c}\text { Ovarian } \\
\text { cysts - } 15 \\
\text { Chronic- } \\
\text { ectopic - } 6\end{array}$ \\
\hline Congenital Anomalies & 5 & 19 \\
\hline
\end{tabular}

Post-operative pain lasted longer in PNS group and surgical site infection were seen more in PNS group.

Type of Pathology

\begin{tabular}{|c|c|c|}
\hline & PNS & DPLS \\
\hline $\begin{array}{c}\text { Duration of Post-Operative } \\
\text { Pain Requiring Analgesics }\end{array}$ & $4-5$ days & $1-2$ days \\
\hline Surgical Site Infection & 34 & 9 \\
\hline Omental Prolapse & - & 3 \\
\hline Duration of Hospital Stay & $48-72$ hrs. & $4-6$ hrs. \\
\hline Incisional Hernia (Late) & 2 & - \\
\hline \multicolumn{2}{|c|}{ Table 4: Post-Operative Complications } \\
\hline
\end{tabular}

Follow-up: No post sterilization pregnancies reported from these study groups.

\section{DISCUSSION}

Of the many methods of female sterilization operations available, minilap tubectomy (PNS) and DPLS operations have stood the test of time and most frequently done in the present times. Other methods namely hysteroscopic tubal occlusions take three months to be effective and are irreversible. Clients need backup contraception for three months and require to confirm tubal block by hysterosalpingogram. Electrocoagulation of tubes through laparoscopy has the danger of visceral burns and future reversal if needed becomes difficult. Vaginal methods are obsolete nowadays for their high morbidity.

The old method of mini laparotomy in the postnatal period had stood the test of time and is still valued as the best with low failure rates. Modified Pomeroy technique is used in the present study, which involves excision of the mid portion of the tube after ligating the tube. The failure of this technique is 1-4 for 1000 cases.(1) A trained MBBS doctor registered under $\mathrm{MCI}$ is eligible to do this surgery. Falope (Silastic) rings are used to occlude fallopian tubes in DPLS.

Only gynaecologists or surgeons with MS degree trained in laparoscopy should do it and such facility is available mostly in urban areas. In the agrarian based Indian Scenario where $70 \%$ of eligible couples come from rural background and where specialist services are minimal, minilap (PNS) still holds promise. When compared to laparoscopic tubal ligation, PNS minilap has certain disadvantages. The incision is longer and may lead to future incisional hernia. Longer exposure of the peritoneal cavity to the exterior may favour microbial invasion and infection. In a study done at Bangladesh, discharge from wound and non-healed wound were $7.7 \%$ and $3.3 \%$.(2) Direct $^{(2)}$ handling of the tissues manually in PNS (Minilap Tubectomy) 
leads to post-operative infection as well as contributes to postoperative pain. The above mentioned study from Bangladesh reports pain in the lower abdomen $28.8 \%$ and fever in $8.8 \%$. Duration of hospital stay is longer in our study for PNS cases.

In comparison, laparoscopic tubal ligation technique (DPLS) is a quicker method and hospital stay is shorter, less than a day. It is an instrumental tubal ligation and therefore handling of tissues is minimal to none. Duration of surgery is less. Essential information from Gupte Hospital states that clients undergoing laparoscopic sterilization can be discharged within 24 hours, causes minimal postop pain and faster recovery and resumption to normal activity. (3) The need for attendants is less in laparoscopy as the stay is very short, a day care surgery.

Regarding failure of laparoscopic sterilization, reports ten year life table cumulative probability of pregnancy per 1000 procedures, as 17.7 in Falope ring application by laparoscopy,

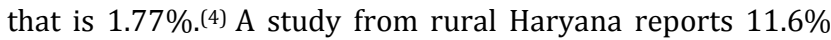
failure for laparoscopic tubal ligation, a higher incidence.(5) In the present study, no failures were reported in both PNS and DPLS groups. Failure can result in a woman having had a coitus when viable sperms can be seen in uterine cavity and tubes and if the client is in pre-menstrual phase with a resultant pregnancy depicted as failure falsely. Hence, clients should be instructed to avoid coitus or use contraception till the date of surgery in laparoscopic method or to come in the post menstrual phase.

A matter of interest to the author of this present study is that, some cases of failure of laparoscopic sterilization done outside were referred for MTP and RPT laparoscopic tubectomy. Intraop findings showed wrongly applied Falope rings on round ligaments, mesosalpinx and omentum or had undergone DPLS during premenstrual phase. There will be a dilemma to do DPLS again in those cases of pregnancy, which resulted in spite successful DPLS surgery because of preexisting nidated pregnancy, which is falsely depicted as failure of DPLS.

The advantages of laparoscopic sterilization are mentioned in the following study.(6) Laparoscopy (DPLS) is the most popular tubectomy method in the non-pregnant women (Interval tubectomy).(5) In addition to small incision, a panoramic view of the peritoneal cavity allows for detecting other pathology like ovarian masses missing IUCDs and provides for managing the same by extending the surgery.

Client satisfaction is good and most suitable for working women with tight schedules. Can be a weekend surgery and back to work without leave of absence. Reversal of laparoscopic tubectomy with restoration of tubal patency is very good. (Essential information from Gupte Hospital)(3). ${ }^{2}$

The disadvantages are need for general anaesthesia in some cases followed by anaesthetic complications and expertise, which has a long learning curve. Only gynaecologists or surgeons with MS degree, trained in laparoscopy should do it and such facility is available mostly in urban areas. According to Berek and Novak's Gynaecology Fourteenth Edition, Page No. 292, pregnancy rates for tubal ring: 1.7 per 1000 women (4). ${ }^{1}$

Other complications exclusive for DPLS is omental prolapse, though it is very minor in nature and can easily be managed. PID leading to tubal oedema and adhesions is a contraindication for DPLS. Visceral injuries while inserting the needle or scope, air embolism, pneumothorax may be theoretical complications.

\section{CONCLUSION}

In conclusion, the present study clearly shows DPLS is more advantageous over PNS (Minilap Tubectomy) and is recommended for all non-pregnant tubal ligations (Interval). Author's personal opinion with permission of the editorial team is that even post-natal cases within 72 hours, where the uterus has involuted up to 12-14 weeks, laparoscopic sterilization can be done with all its advantages and preventing few minilap disadvantages in a tertiary care centre with good surgical expertise.

\section{REFERENCES}

1. Shephard MK. Female contraceptive sterilization. Obstet Gynaecol Surve 1974;29(11):739-87.

2. Sabera Rahman, Husn Ara Li, Nina Homaira Naznin, et al. Complications side effects and satisfaction of the interval and post MR tubectomy clients: a comparative study. The ORION 1999;3. www.oriongroup.net/journals/journals/vol3_May1999/12.htm.

3. FAQ- Tubectomy: Essential information. http:gupte hospital.com/indexphp? Option=com_content $\%$ view=article $\&$ id $=102$

4. Peterson HB, Xia Z, Hughes JM, et al. The risk of pregnancy after tubal sterilization: findings from the U.S Collaborative review of sterilization. AM J Obstet Gynaecol 1996;174(4):1161-8.

5. Malik S, Rathee S, Singh S. Declining popularity of laparoscopic tubectomy, why? Trop Doct 1992;22(3):11920.

6. Tubectomy is surgical procedure for permanent contraception to prevent future. Amazing Body Facts. Consumer Protection Act. Health Survey. Know Your Body. Print Oath. World Health Days MedIndia » Surgical Procedures » Overview. Nomenclatures: Tubectomy, Tubal Sterilization, Female Sterilization.

http://www.medindia.net/surgicalprocedures/tubectom y.htm 